\title{
DISSECTION OF TUMOR-NECROSIS FACTOR- $\alpha$ INHIBITION OF LONG- TERM POTENTIATION (LTP) REVEALS A p38 MITOGEN-ACTIVATED PROTEIN KINASE-DEPENDENT MECHANISM WHICH MAPS TO EARLY—BUT NOT LATE-PHASE LTP
}

\author{
M. P. BUTLER, ${ }^{\text {a,b }}$ J. J. O'CONNOR ${ }^{\mathrm{a}}$ AND \\ P. N. MOYNAGH ${ }^{\text {* }}$ \\ ${ }^{a}$ Department of Human Anatomy and Physiology, Conway Institute of \\ Biomolecular and Biomedical Research, University College Dublin, \\ Earlsfort Terrace, Dublin 2, Ireland \\ ${ }^{b}$ Department of Pharmacology, Conway Institute of Biomolecular and \\ Biomedical Research, University College Dublin, Belfield, Dublin 4, \\ Ireland
}

\begin{abstract}
The pro-inflammatory cytokine tumor-necrosis factor- $\alpha$ (TNF- $\alpha)$ is elevated in several neuropathological states that are associated with learning and memory deficits. Previous work has reported that TNF- $\alpha$ inhibits the induction of LTP in areas CA1 [Neurosci Lett 146 (1992) 176] and dentate gyrus [Neurosci Lett 203 (1996) 17]. The mechanism(s) underlying this process of inhibition have not to date been addressed. Here, we show that perfusion of TNF- $\alpha$ prior to long-term potentiation (LTP) inducing stimuli inhibited LTP, and that in late-LTP ( $3 \mathrm{~h}$ post-tetanus) a depression in synaptic field recordings was observed $(68 \pm 5 \%, n=6$ versus control $175 \pm 7 \%, n=6, P<0.001)$. We investigated the involvement of the mitogen-activated protein kinase (MAPK) p38 in the inhibition of LTP by TNF- $\alpha$ as p38 MAPK has previously been shown to be involved in interleukin-1 $\beta$ inhibition of LTP in the dentate gyrus [Neuroscience 93 (1999b) 57]. Perfusion of TNF- $\alpha$ led to an increase in the levels of phosphorylated p38 MAPK detectable in the granule cells of the dentate gyrus. The p38 MAPK inhibitor SB $203580(1 \mu \mathrm{M})$ was found by itself to have no significant effect on either early or late phase LTP in the dentate gyrus. SB 203580 was found to significantly reverse the inhibition of early LTP by TNF- $\alpha$ (SB/TNF- $\alpha 174 \pm 5 \%, n=6$ versus TNF- $\alpha 120 \pm 7 \%, n=6$, $P<0.001,1 \mathrm{~h}$ post-tetanus) to values comparable to control LTP (control $175 \pm 7 \%, n=6$ ). Interestingly however, the depressive effects of TNF- $\alpha$ on late LTP $(2-3 \mathrm{~h})$ were clearly not attenuated by p38 MAPK inhibition (SB/TNF- $\alpha 132 \pm 5 \%, n=6$ versus control LTP $175 \pm 7 \%, n=6, P<0.001,3 \mathrm{~h}$ post-tetanus). This work suggests that TNF- $\alpha$ inhibition of LTP represents a biphasic response, a p38 MAPK-dependent phase that coincides with the early phase of LTP and a p38 MAPK independent phase that temporally maps to late LTP. (c) 2004 IBRO. Published by Elsevier Ltd. All rights reserved.
\end{abstract}

Key words: cytokines, long-term potentiation, memory, MAPK.

\footnotetext{
*Corresponding author. Tel: +353-1-716-6761; fax: +353-1-269-2749.

E-mail address: p.moynagh@ucd.ie (P. N. Moynagh).

Abbreviations: aCSF, artificial cerebrospinal fluid; fEPSP, field excitatory post-synaptic potential; HFS, high frequency stimulation; IL-1 $\beta$, interleukin-1 $\beta$; JNK, c-Jun $\mathrm{N}$ terminal kinase; LTD, long-term depression; LTP, long-term potentiation; MAPK, mitogen-activated protein kinase; NMDA, $N$-methyl-D-aspartate; TNF- $\alpha$, tumor-necrosis factor- $\alpha$; VDCC, voltage-dependent calcium channel.
}

Research into many molecules originally thought to be specific to the immune system has revealed interesting findings of their plasticity-related functions in the CNS (Albensi and Mattson, 2000; Andreasson et al., 2001; Boulanger et al., 2001; Chen et al., 2002; Chun, 2001; Cunningham et al., 1996; lida et al., 2000). One such molecule is tumor-necrosis factor (TNF)- $\alpha$, brain levels of which are found to be elevated in a number of cognitive diseases (lida et al., 2000; Kassiotis and Kollias, 2001; Sriram et al., 2002). TNF- $\alpha$ and interleukin-1 $\beta$ (IL-1 $\beta$ ) at pathophysiological levels have been shown to inhibit long-term potentiation (LTP) in the CA1 and dentate gyrus regions of the rat hippocampus (Cunningham et al., 1996; Murray and Lynch, 1998; Tancredi et al., 1992). LTP is a long lasting increase in synaptic efficacy, which is thought to be an important underlying mechanism of learning and memory formation (Bliss and Collingridge, 1993). LTP in the CA1 region and dentate gyrus is dependent on $\mathrm{Ca}^{2+}$ influx through the $\mathrm{N}$-methyl-D-aspartate (NMDA) receptor channel during tetanic stimulation, and IL-1 $\beta$ has been shown to depress NMDA receptor-mediated field potentials in the dentate gyrus (Coogan and O'Connor, 1997) which may contribute to impaired $\mathrm{Ca}^{2+}$ influx (Cunningham et al., 1996). IL-1 $\beta$ has also been shown to inhibit voltage-dependent calcium channel (VDCC) function in the CA1 by a pertussis toxin-sensitive G-protein-coupled-protein kinase C mechanism (Plata-Salaman and Ffrench-Mullen, 1992, 1994), and VDCCs have been implicated in the expression of LTP in the CA1 region of the hippocampus. The p38 MAPK has been implicated in mediating the depression by IL-1 $\beta$ on both LTP- and NMDA-receptor-mediated transmission (Coogan et al., 1999b). More recently a role for the p38 MAPK in metabotropic-glutamate receptor-dependent long-term depression (LTD) has been demonstrated in the CA1 region of neonates (Bolshakov et al., 2000). Interestingly, TNF- $\alpha$ receptor knockout mice demonstrate an impairment of LTD in the CA1 region, mimicked by $\kappa B$ decoy DNA, which implicates the TNF-NFKB signaling pathway in LTD (Albensi and Mattson, 2000). Recent investigations into the signaling mechanisms whereby TNF- $\alpha$ is involved in pathological pain states uncovered interesting findings of PKA-dependent responses in rat sensory neurons (Zhang et al., 2002), and in another study showed p38 MAPK and c-Jun $\mathrm{N}$ terminal kinase (JNK) activation accompanied by a transient increase in $\mathrm{Ca}^{2+}$ release from ryanodine-sensitive intracellular stores in dorsal root ganglion neurones (Pollock et al., 2002). TNF- $\alpha$ has also been

0306-4522/04\$30.00+0.00 ๑ 2004 IBRO. Published by Elsevier Ltd. All rights reserved. doi:10.1016/j.neuroscience.2003.11.040 


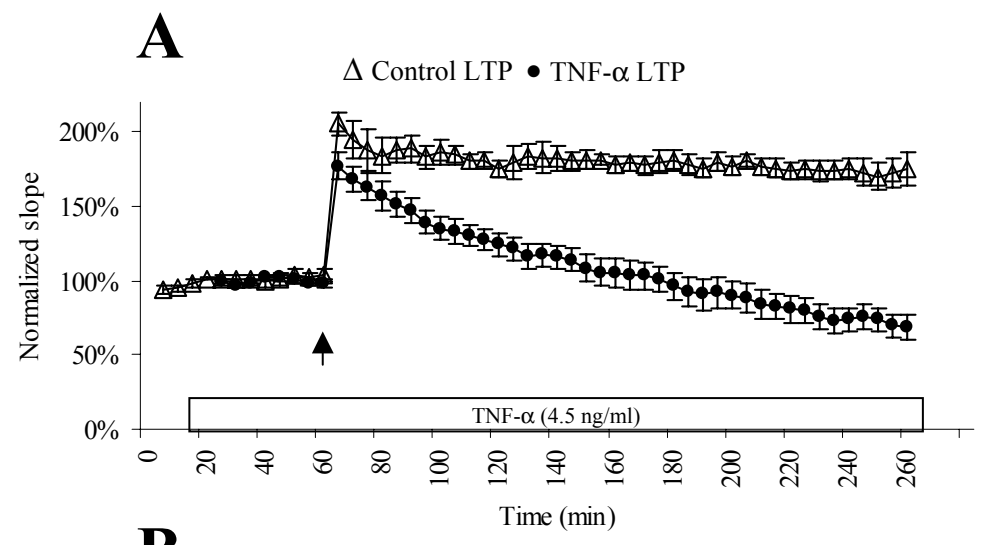

B

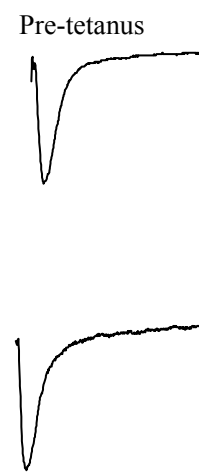

Control LTP

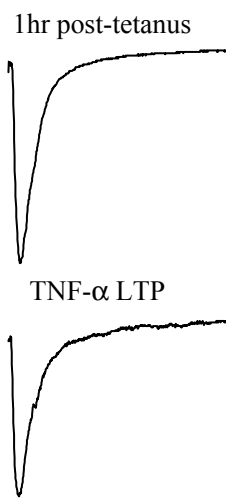

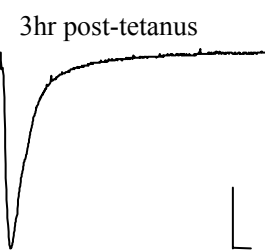

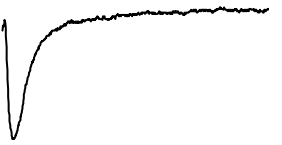

Fig. 1. Time-course of the effect of TNF- $\alpha$ on early and late-phase LTP. (A) Bath application of TNF- $\alpha$ ( $4.5 \mathrm{ng} / \mathrm{ml})$ to hippocampal slices $20 \mathrm{~min}$ pre-HFS (eight trains of eight pulses at $200 \mathrm{~Hz})$ led to an inhibition in the expression of LTP $(120 \pm 7 \% 1 \mathrm{~h}$ post-tetanus, $(\bullet), n=6$ in TNF- $\alpha$-treated slices compared with $175 \pm 6 \%$ in control slices, $(\Delta), n=6, P<0.001)$. Recordings of fEPSPs were followed for $3 \mathrm{~h}$ post-tetanus in these TNF- $\alpha$-treated slices and as shown a depression in the fEPSP response was observed $(68 \pm 5 \% 3 \mathrm{~h}$ post-tetanus, $n=6$ in TNF- $\alpha$-treated slices versus $175 \pm 7 \%$ in control slices, $n=6, P<0.001$ ). Control, $\Delta ; \mathrm{TNF}-\alpha, \boldsymbol{\bullet}$. Open bars represent the period of perfusion of the cytokines. HFS is denoted by the arrow. (B) Traces show representative fEPSPs traces taken $5 \mathrm{~min}$ before (left trace), $1 \mathrm{~h}$ post-tetanus (middle trace) and $3 \mathrm{~h}$ post-tetanus in control LTP and TNF- $\alpha / \mathrm{LTP}(4.5 \mathrm{ng} / \mathrm{ml})$ experiments. Scale bar $=5 \mathrm{~ms}$ (horizontal); vertical $=0.5 \mathrm{mV}$. The traces shown represent the average of three sample traces.

shown to lead to an enhancement of synaptic transmission through increasing the surface expression of AMPA receptors (Beattie et al., 2002). Altogether these findings show that the neuromodulatory effects of TNF- $\alpha$ are varied and complex.

This study aimed to initially examine the effects of TNF- $\alpha$ on both the early (approximately $1 \mathrm{~h}$ post-induction) and late phases of LTP ( $3 \mathrm{~h}$ post-tetanus), and then to assess the role of p38 MAPK in mediating TNF- $\alpha$ inhibitory effects on LTP. These studies for the first time show that TNF- $\alpha$ inhibits early-LTP by a p38 MAPK-dependent mechanism, similar to that found for IL-1 $\beta$. However lateLTP is inhibited by a mechanism independent of p38 MAPK.

\section{EXPERIMENTAL PROCEDURES}

Transverse hippocampal slices $(350 \mu \mathrm{m})$ were prepared by standard methods from adult male Wistar rats $(50-80 \mathrm{~g})$. Briefly, slices were equilibrated for at least $1 \mathrm{~h}$ in a holding chamber at room temperature, $\mathrm{pH} 7.4$, in oxygenated artificial cerebrospinal fluid (aCSF; composition in $\mathrm{mM}: \mathrm{NaCl}, 120 ; \mathrm{KCl}, 2.5 ; \mathrm{MgSO}_{4}, 2$; $\mathrm{CaCl}_{2}, 2 ; \mathrm{NaHCO}_{3}, 26 ; \mathrm{NaH}_{2} \mathrm{PO}_{4}, 1.25$; D-glucose, 10) before being transferred to a recording chamber perfused with aCSF at a flow rate of $5-7 \mathrm{ml} / \mathrm{min}$ at $29-30{ }^{\circ} \mathrm{C}$. Extracellular recordings of field excitatory post-synaptic potentials (fEPSP) were elicited by stimulation of the medial perforant path of the dentate gyrus by a monopolar glass electrode at a frequency of $0.05 \mathrm{~Hz}$. Responses were recorded by a glass electrode placed in the middle third of the molecular layer in the presence of $100 \mu \mathrm{M}$ of the $\mathrm{GABA}_{\mathrm{A}}$ receptor antagonist picrotoxin (Sigma-Aldrich Ireland Ltd, Dublin, Ireland) and stimulus strength was adjusted to give a response $35 \%$ of maximal. Stable baseline recordings were made for at least 10 min prior to application of drugs. LTP was induced by high frequency stimulation (HFS) consisting of eight trains of eight pulses at $200 \mathrm{~Hz}$ at 2-s intervals at a stimulus strength corresponding to $75 \%$ of maximal. Recordings were analyzed off-line using the Strathclyde electrophysiology software (J. Dempster, Edinburgh, UK).

Recombinant rat TNF- $\alpha$ (R \& D Systems, UK) was prepared in sterile PBS containing 0.1\% BSA (Sigma-Aldrich Ireland Ltd.). Stable baseline recordings (20 $\mathrm{min}$ ) were obtained before application of TNF- $\alpha(4.5 \mathrm{ng} / \mathrm{ml})$. Additional drugs used included SB 203580 (Calbiochem, UK) dissolved in dimethylsulphoxide to a final concentration of $1 \mu \mathrm{M}$.

For immunostaining, the hippocampus was dissected out following bath application of the drugs and immersed in $4 \%$ paraformaldehyde at $4{ }^{\circ} \mathrm{C}$ for overnight fixation. Slices were then re- 


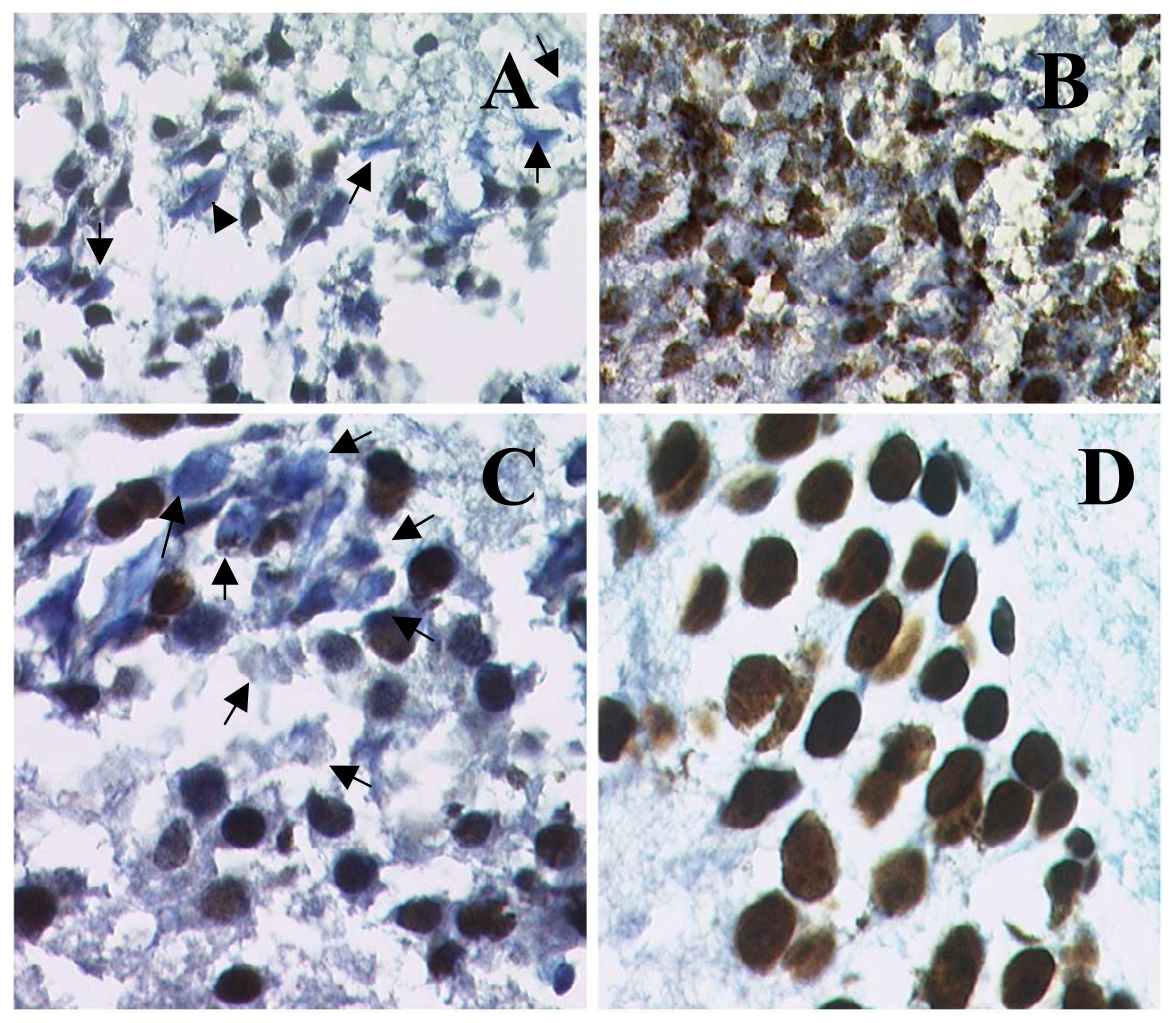

Fig. 2. TNF- $\alpha$ leads to more intense immunostaining for activated p38 MAPK in the dentate gyrus region of rats aged $4-5$ week old compared with control slices. (A) Control hippocampal slices showing basal levels of activated p38 in the granule cells (40× magnification) and (C) control at higher magnification $(63 \times)$. Arrows indicate cells that show no obvious immunostaining for $p-p 38$. (B) TNF- $\alpha(4.5 \mathrm{ng} / \mathrm{ml})$ perfused through the hippocampal slice for 30 min leads to an increase in the number of cells showing immunochemical staining for p-p38 as well as more intense staining. (D) Shows a TNF- $\alpha$-treated slice at a higher magnification $(63 \times)$.

moved and passed through a series of graded sucrose solutions $(5 \%, 15 \%, 30 \%)$ to facilitate cryoprotection. Sections were removed from the sucrose solution, embedded in OCT and then cut at a thickness of $10 \mu \mathrm{M}$ by a cryostat set at a cutting temperature of $-16{ }^{\circ} \mathrm{C}$. Sections were then mounted onto silanized slides. For detection of active p38 MAP kinase, phosphospecific anti-p38 (mouse monoclonal lgG2 subclass; $5 \mu \mathrm{g} / \mathrm{ml}$; Sigma), that reacts specifically with the active doubly phosphorylated form of p38 MAPK and its related isoforms was used (Sigma, St Louis, USA). It does not recognize the non-phosphorylated and mono-phosphorylated forms of the p38 MAPK molecule or the non-, mono- or diphosphorylated forms of JNK and ERK MAPK. The binding of the antibody to its respective epitope was visualized using the Vectastain Elite ABC kit (Vector Laboratories, CA, USA) according to the manufacturer's recommendations with the exception of an additional step. For phospho-p38 MAPK the concentration of the secondary biotinylated antibody was $2.5 \mu \mathrm{g} / \mathrm{ml}$. The chromagen diaminobenzidine tetrahydrochloride (Sigma-Aldrich Ireland Ltd.) was used which produces a brownish precipitate, the counterstain used was hematoxylin, which stains nuclear chromatin blue. For non-immune control, a mouse IgG antibody (Chemicon International Ltd., UK) was used as the primary antibody. In such slides no brown staining corresponding to p-p38 MAPK was seen, with only counterstaining apparent by hematoxylin. Slides were analyzed on a microscope equipped with Axiovision software.

All data are expressed as mean \pm S.E.M. In all experiments examining LTP, all data points represent $5 \mathrm{~min}$ averages. For statistical analysis of data, two-tailed paired Student's $t$-tests were employed to test significance between baseline and post-treatment values, and two-tailed unpaired Student's $t$-test was employed for comparisons between different test and control slices.

\section{RESULTS}

\section{Effects of TNF- $\alpha$ on tetanically induced LTP}

LTP was generated by applying HFS (eight trains of eight pulses at $200 \mathrm{~Hz}$ ) to the medial perforant path of the dentate gyrus that led to a robust LTP persisting for at least $3 \mathrm{~h}$ post-tetanus (fEPSP $175 \pm 7 \%, n=6,3 \mathrm{~h}$ post-tetanus versus $1 \mathrm{~h}$ post-tetanus $175 \pm 6 \%, n=6$; Fig. $1 \mathrm{~A}$ ). In some slices, this potentiation lasted for up to $6 \mathrm{~h}$ (data not shown). When TNF- $\alpha(4.5 \mathrm{ng} / \mathrm{ml})$ was applied to the hippocampal slice 20 min pre-tetanus early-LTP (TNF- $\alpha /$ LTP $120 \pm 7 \%, n=6$ versus control LTP $175 \pm 6 \%, n=61 \mathrm{~h}$ post-tetanus, $P<0.001)$ was significantly impaired as previously published (Butler et al., 2002). The LTP was followed in these TNF- $\alpha$ treated slices for $3 \mathrm{~h}$ post-tetanus corresponding to late LTP, and the fEPSP recordings were seen to decrease below baseline fEPSP values and plateaued at approximately $3 \mathrm{~h}$ post-tetanus (TNF- $\alpha / \mathrm{LTP}$ fEPSP $68 \pm 5 \%, n=6$ versus control LTP $175 \pm 7 \%, n=6$, $P<0.001)$.

\section{Effects of TNF- $\alpha$ on levels of p-p38 MAPK in the dentate gyrus}

In order to explore the potential role of p38 MAPK in mediating the inhibitory effects of TNF- $\alpha$ on LTP it was first necessary to show that the latter could activate $p 38$. We 


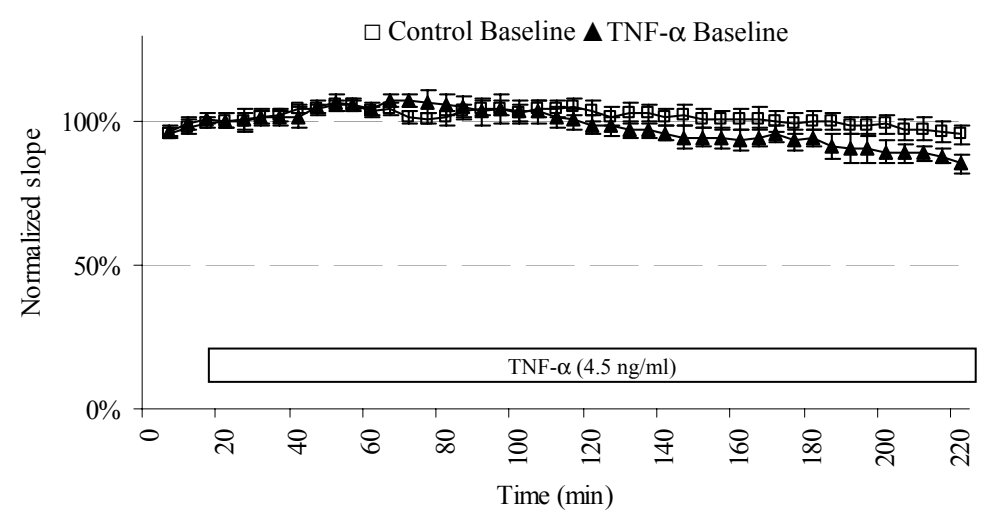

$\Delta$ Control LTP $\square$ SB LTP

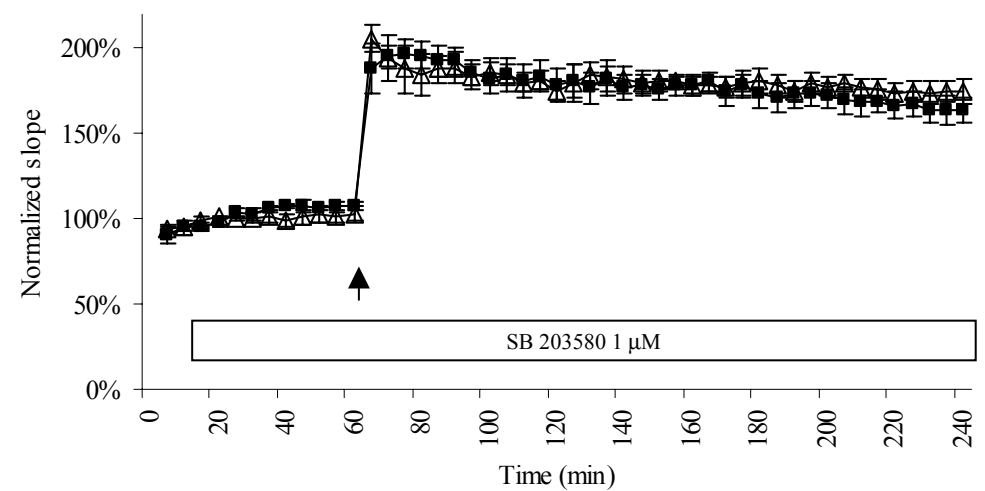

Fig. 3. (A) Application of TNF- $\alpha$ alone does not mimic the depression seen in HFS-TNF- $\alpha$ pre-treated hippocampal slices. TNF- $\alpha$ (4.5 ng/ml) was added at time $20 \mathrm{~min}$ and remained in for the duration of the experiment (220 min total). At time $220 \mathrm{~min}$ the fEPSP response in TNF- $\alpha$ baseline was significantly different from TNF- $\alpha /$ LTP slices (TNF- $\alpha$ Baseline $86 \pm 3 \%,(\mathbf{\Lambda}), n=6$ versus $68 \pm 5 \%, n=6$ in TNF- $\alpha / L T P$ slices, $P<0.05$ ). TNF- $\alpha$ baseline is not significantly different from control baseline over the time period investigated (TNF- $\alpha$ baseline $86 \pm 3 \%, n=6$ versus control baseline $96 \pm 3 \%$, ( $\square$ ), $n=6$, at time $220 \mathrm{~min} P>0.05)$. Control baseline, $\square$; TNF- $\alpha$ Baseline, $\boldsymbol{\Delta}$. Open bars represent the time period of cytokine perfusion. (B) The p38 MAPK inhibitor SB $203580(1 \mu \mathrm{M})$ does not affect early $(1 \mathrm{~h})$ or late (approximately $3 \mathrm{~h}$ ) phase LTP in the dentate gyrus. SB $203580(1 \mu \mathrm{M})$ was added at time $10 \mathrm{~min}$ and was present throughout the duration of the experiment. It led to a small though not significant increase in baseline synaptic transmission. SB 203580 was found not to affect either early-LTP $(178 \pm 9 \% 1 \mathrm{~h}$ post-tetanus $(\boldsymbol{\square}), n=5$ in SB 203580 treated slices compared with control $175 \pm 6 \% 1 \mathrm{~h}$ post-tetanus, $(\Delta), n=6, P>0.7)$ or late-LTP $(163 \pm 7 \% 3 \mathrm{~h}$ post-tetanus in SB 203580 treated slices, $n=5$ compared with $175 \pm 7 \%$ in control slices, $P>0.2$ ). SB 203580 LTP, $\mathbf{\square}$; Control LTP, $\Delta$; open bar represents the time of drug perfusion.

first examined the levels of diphosphorylated p38 MAPK in the dentate granule cells of untreated rat hippocampal slices. As can be seen (Fig. 2A, 2C) prominent immunostaining was observed $(40 \times / 63 \times$ magnification). Therefore phospho-p38 MAPK is present at high basal levels in the granule cells of rats aged 4-5 weeks. Next, we perfused TNF- $\alpha$ (4.5 $\mathrm{ng} / \mathrm{ml})$ through hippocampal slices and examined the activation status of p-p38 MAPK $30 \mathrm{~min}$ post-drug addition. TNF- $\alpha$ led to more intense and widespread immunochemical staining for p-p38 MAPK in the granule cells (Fig. 2B, 2D) when compared with untreated slices.

\section{Effects of TNF- $\alpha$ on baseline synaptic transmission}

The effects of TNF- $\alpha(4.5 \mathrm{ng} / \mathrm{ml})$ on baseline synaptic transmission was studied in order to determine if TNF- $\alpha$ depressive effects on late-LTP could be mirrored by TNF- $\alpha$ application alone (Fig. 3A). TNF- $\alpha$ was added at time 20 min and recordings of the fEPSPs measured for $200 \mathrm{~min}$ post-drug addition, this time matched the time-course of TNF- $\alpha$ application in the LTP studies. A comparison was made between TNF- $\alpha$ and test control on baseline synaptic transmission, no significant difference was found at the time-points examined (TNF- $\alpha$ baseline $86 \pm 3 \%, n=6$ versus control baseline $96 \pm 3 \% n=6$, at time $220 \mathrm{~min}$, $P>0.05$; Fig. 3A). Control baseline was found to be significantly different from TNF- $\alpha /$ LTP (TNF- $\alpha / L T P \quad 68 \pm 5 \%$, $n=6$ versus control baseline $96 \pm 3 \% n=6, P<0.01)$.

\section{Effects of SB 203580 on LTP in the dentate gyrus}

The p38 MAPK inhibitor SB $203580(1 \mu \mathrm{M})$ when added 50 min prior to application of tetanic stimulation led to a small, although not significant increase in baseline synaptic transmission ( $P>0.05$; Fig. 3B). Following high-frequency stimulation, the magnitude of LTP in SB 203580-treated slices as measured 60 min post-tetanus, was found to be indistinguishable from control LTP (SB-LTP 178 \pm \% $1 \mathrm{~h}$ post-tetanus, $n=5$ versus control $175 \pm 6 \%, n=6)$. The effects of SB 203580 on late-LTP was examined and again no significant difference was observed between control and SB-treated slices (SB-LTP $163 \pm 7 \% 3 \mathrm{~h}$ post-tetanus, $n=5$ versus control LTP $175 \pm 7 \%, n=6, P>0.2$ ). 

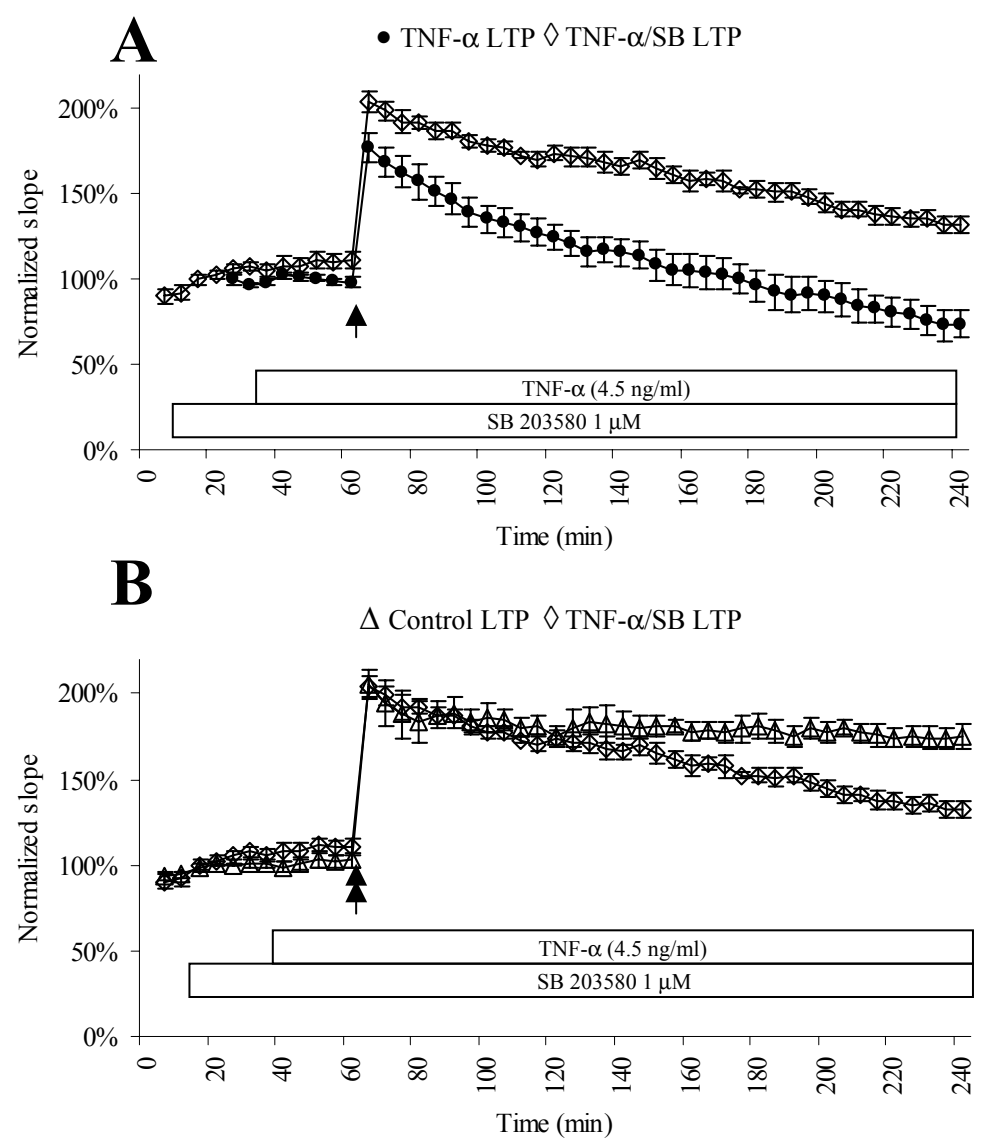

Fig. 4. The p38 MAP kinase inhibitor SB 203580 reverses the early but not late-phase mediated inhibition of LTP by TNF- $\alpha$. (A) In SB/TNF- $\alpha$ treated slices, SB $203580(1 \mu \mathrm{M})$ was added at time $10 \mathrm{~min}$, TNF- $\alpha(4.5 \mathrm{ng} / \mathrm{ml})$ at time $40 \mathrm{~min}$, and HFS was delivered to the slice at time $60 \mathrm{~min}$. SB 203580 was seen to reverse the inhibitory effect of TNF- $\alpha$ at $1 \mathrm{~h}$ post-tetanus $(174 \pm 5 \%,(224), n=6$ in SB/TNF- $\alpha$-treated slices compared with $120 \pm 7 \%$ in TNF- $\alpha$-treated slices $(\mathbf{\theta} ; n=6 P<0.001)$. At $3 \mathrm{~h}$ post-tetanus SB 203580 had a reduced but still highly significant antagonistic effect on TNF- $\alpha$-mediated depression of LTP $(132 \pm 5 \%$ in SB/TNF- $\alpha$-treated slices, $n=6$ compared with $68 \pm 5 \%, n=6$ in TNF- $\alpha$-treated slices, $P<0.001)$. (B) SB 203580 reverses the inhibition of LTP by TNF- $\alpha$ at $1 \mathrm{~h}$ post-tetanus to values similar to control (SB/TNF- $\alpha$-treated slices $174 \pm 5 \%, n=6$ in SB/TNF- $\alpha$-treated slices versus control LTP $175 \pm 6 \% 1 \mathrm{~h}$ post-tetanus, $n=6$ ). At $3 \mathrm{~h}$ post-tetanus fEPSP responses in SB pre-treated TNF- $\alpha$ slices are significantly different from control LTP values $(132 \pm 5 \%, n=6$ compared with $175 \pm 7 \%, n=6$ in control, $P<0.001)$. Control LTP, $\Delta ;$ TNF- $\alpha, \bullet ;$ SB/TNF- $\alpha, \diamond$. Open bars represent the period of perfusion of the designated cytokine/drug. HFS is represented by the arrow.

\section{Effects of SB 203580 on inhibition of LTP by TNF- $\alpha$}

When slices were incubated with SB $203580(1 \mu \mathrm{M}) 30$ min prior to TNF- $\alpha$ addition and for the remainder of the experiment the impairment of early-LTP by TNF- $\alpha$ was significantly attenuated (Fig. 4A; SB/TNF- $\alpha 174 \pm 5 \%, n=6$, $1 \mathrm{~h}$ post-tetanus compared with $120 \pm 7 \%$ in TNF- $\alpha$ treated slices, $P<0.001)$. Indeed at $1 \mathrm{~h}$ post-tetanus the SB/TNF- $\alpha$ LTP was found to be indistinguishable from control LTP (SB/TNF- $\alpha 174 \pm 5 \%, n=6$ versus control $175 \pm 7 \%, n=6$ ). A decline in the magnitude of the fEPSP slope was seen in the SB/TNF- $\alpha$-treated slices (Fig. 4B), relative to control LTP, which emerged at $1.5 \mathrm{~h}$ post-tetanus (SB/TNF- $\alpha$ $165 \pm 6 \%, n=6$ compared with control $181 \pm 6 \%, n=6)$ and became significant at $2 \mathrm{~h}$ post-tetanus (SB/TNF- $\alpha$ $153 \pm 5 \%, n=6$ compared with control LTP $181 \pm 7 \%, n=6$, $P<0.01)$ and which continued to further in significance by $3 \mathrm{~h}$ post-tetanus (SB/TNF- $\alpha 132 \pm 5 \%, n=6$ versus control LTP $175 \pm 7 \%, n=6, P<0.001)$. These results suggest that TNF inhibits the early phase of LTP by a p38-dependent mechanism and negatively affects late-LTP by a mechanism independent of p38. A summary of the effects of SB203580 on inhibition of LTP by TNF- $\alpha$ is shown in Fig. 5.

\section{DISCUSSION}

LTP is known to consist of distinct temporal phases that involve different molecular mechanisms for their expression in the CA1 and dentate gyrus regions of the hippocampus (Sweatt, 1999). There is an initial phase generally referred to as short-term potentiation that is independent of protein kinase activity and lasts approximately 30 min followed by early phase, designated early LTP that is over by approximately $1-2 \mathrm{~h}$ that is independent of protein synthesis, and dependent on such kinases as CaMKII and PKC. A later more persistent phase designated late LTP requires new protein synthesis and is PKA dependent (Abel et al., 1997; Frey et al., 1993; Huang and Kandel, 

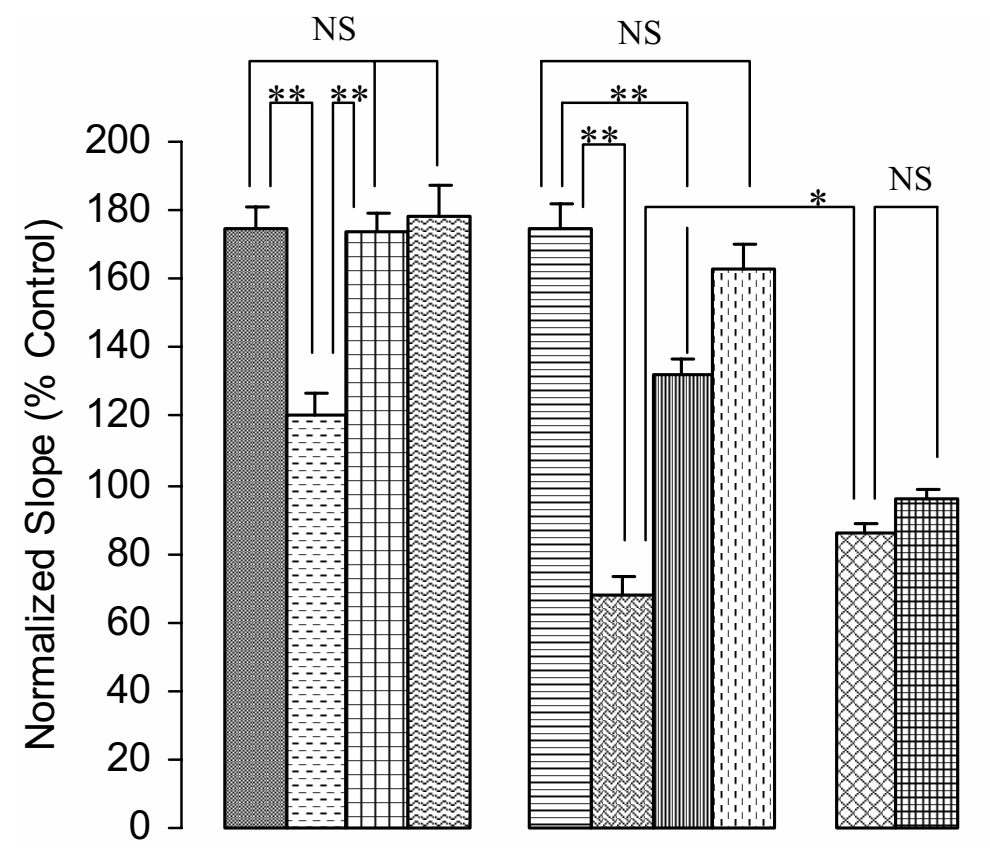

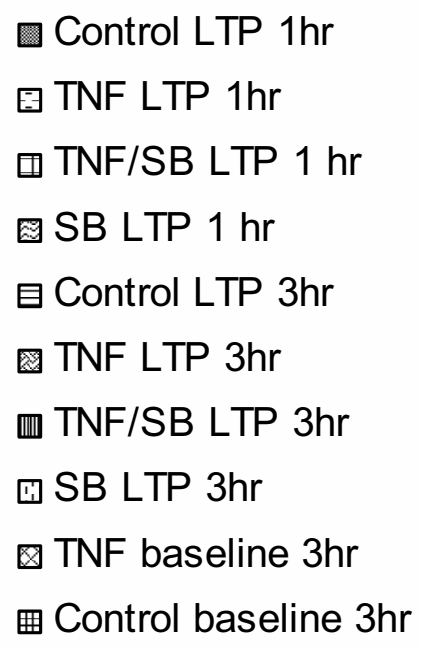

Fig. 5. Summarizing the effects of the p38 MAPK inhibitor SB 203580 on both TNF- $\alpha$ inhibition of LTP and control LTP at $1 \mathrm{~h}$ and $3 \mathrm{~h}$ post-tetanus. The effect of TNF- $\alpha$ on baseline synaptic transmission is also depicted. Normalized slope of the fEPSP was measured at $1 \mathrm{~h}$ and at $3 \mathrm{~h}$ where indicated after application of tetanus in slices. Mean \pm S.E.M. are shown for each condition $(n=6)$. ** Represents $P<0.001$, * represents significance of $P<0.05$, NS represents not significant $P>0.05$. ${ }^{* *}$ TNF- $\alpha$ significantly impairs LTP at $1 \mathrm{~h}$ post-tetanus, ${ }^{* *}$ SB 203580 attenuates TNF- $\alpha$ inhibition of early-LTP to values comparable to control LTP (difference not significant). At $3 \mathrm{~h}$ post-tetanus ${ }^{* *} \mathrm{TNF}-\alpha$ has a significant depressive effect on LTP, ${ }^{* *}$ SB 203580 pre-treated TNF- $\alpha$ slices are however significantly different from control LTP at this later time-point. SB 203580 did not affect control LTP at $1 \mathrm{~h}$ or $3 \mathrm{~h}$ post-tetanus, fEPSP values were comparable to control LTP. Baseline synaptic responses were examined, the fEPSP reponses in slices perfused with TNF- $\alpha$ were not significantly different from control baseline at $3 \mathrm{~h}$ post-drug addition. ${ }^{*} \mathrm{TNF}-\alpha$ baseline was however significantly different from TNF- $\alpha / L T P$ at time corresponding to $3 \mathrm{~h}$ post-tetanus.

1994; Nguyen and Kandel, 1996; Otani and Abraham, 1989).

The neurobiological impact of the pro-inflammatory cytokine TNF- $\alpha$ is increasingly being recognized because of the plethora of information now available on its neuropathological as well as its physiological effects. We show in this study that TNF- $\alpha$ at pathophysiological concentrations $(4.5 \mathrm{ng} / \mathrm{ml})$ inhibited the induction of LTP, as reported previously in the CA1 and dentate gyrus region of the hippocampus (Cunningham et al., 1996; Tancredi et al., 1992). However these earlier studies did not address later stages ( $>1 \mathrm{~h}$ after induction). In this study we decided to examine the effects of TNF- $\alpha$ on early and late-LTP by following the electrophysiological response for $3 \mathrm{~h}$ posttetanus. In so doing, a synaptic depression was unveiled which stabilized at approximately $3 \mathrm{~h}$ post-tetanus. This has not been previously reported in TNF- $\alpha$ - or IL-1 $\beta$ treated slices. However a similar electrophysiological depressive phenomenon has been reported previously with the cytokine interferon- $\alpha$ in the CA1 region (MendozaFernandez et al., 2000). In order to address whether this depression could be effected by bath application of this cytokine without application of HFS we followed the electrophysiological response of slices perfused with TNF- $\alpha$ for approximately $3 \mathrm{~h}$. We found that TNF- $\alpha$ baseline responses were statistically different from TNF- $\alpha$ LTP at points corresponding to $3 \mathrm{~h}$ post-tetanus. No significant difference was noted between control and TNF- $\alpha$ baseline responses for the same time-point investigated. As such we can conclude that HFS must activate signaling mechanisms that facilitate the depression observed in TNF- $\alpha$ treated hippocampal slices.

TNF- $\alpha$ has previously been shown to activate a family of mitogen-activated protein kinases (MAPK), which include p42/44, p38 and c-Jun N-terminal kinase (JNK; Vandenabeele et al., 1995). The p42 MAPK has been shown to be important in the induction of NMDA-receptor-dependent LTP in the CA1 (English and Sweatt, 1996) and dentate gyrus (Coogan et al., 1999a). In contrast, it has been shown that p38 MAPK is an integral signaling component in metabotropic glutamate receptor dependent LTD, first demonstrated in the CA1 of neonates (Bolshakov et al., 2000) and later in the dentate gyrus region of the rat hippocampus (Murray and O'Connor, 2003). The p38 MAPK is not involved in the induction of NMDA receptor dependent early LTP, as reported previously (Coogan et al., 1999b), nor is it involved in the induction of late LTP (3 h post-tetanus), as SB/LTP fEPSP values were found to be comparable to control LTP at $1 \mathrm{~h}$ and $3 \mathrm{~h}$ post-tetanus. Another stress-activated protein kinase, JNK, has recently been shown by this laboratory to be involved in LTD in the dentate gyrus, and similar to p38 MAPK was shown not to influence LTP (Curran et al., 2003). Therefore p42 MAPK and $\mathrm{p} 38 / \mathrm{JNK}$ appear to have contrasting physiological roles in the hippocampal synaptic plasticity processes of LTP and LTD. 
We set out to investigate whether p38 MAPK could possibly be involved in mediating TNF- $\alpha$ inhibition of LTP. First, we examined the levels of activated p38 MAPK in the dentate gyrus region of the hippocampus of young rats (4 weeks). Using antibody that recognizes dually phosphorylated p38 MAPK, strong immunostaining of the granule cells in the dentate gyrus was observed (Fig. 2A, 2C), indicating high basal levels, as well as marked immunostaining of the pyramidal neurons in the CA1 and CA3 regions (data not shown). TNF- $\alpha$ was perfused through hippocampal slices and led to an increase in the level of immunostaining (Fig. 2B, 2D). This is not surprising since TNF- $\alpha$ is known to lead to the activation of p38 MAPK. The specific p38 MAPK inhibitor SB $203580\left(\mathrm{IC}_{50}=600 \mathrm{nM}\right.$ in cells) was used in this study at a final concentration of $1 \mu \mathrm{M}$, as doses of $0.6 \mu \mathrm{M}$ were found to prevent the phosphorylation of heat-shock protein-27 in response to IL-1 $\beta$, cellular stresses and bacterial endotoxins in vivo (Cuenda et al., 1995). We found that p38 MAPK is involved in the inhibition of LTP by TNF- $\alpha$ but importantly that $\mathrm{p} 38$ MAPK inhibition does not reverse the impairment of lateLTP by TNF- $\alpha$ ( $>80$ min post-tetanus). This only became apparent due to the long follow-up of $3 \mathrm{~h}$ post-tetanus undertaken in this study. The synaptic response measured by fEPSP recordings were seen to decline from approximately $1 \mathrm{~h}$ and at $2 \mathrm{~h}$ post-tetanus a statistical significant difference between control LTP and SB/TNF- $\alpha$-LTP was observed $(P<0.01)$, which furthered in significance by the $3 \mathrm{~h}$ time-point $(P<0.001)$. Could this later-phase possibly represent a protein-synthesis dependent mechanism of inhibition of LTP by TNF- $\alpha$ ? Indeed, the time-course coincides with late LTP, which has now been firmly established to be dependent on new protein synthesis (Frey et al., 1993; Huang and Kandel, 1994; Nguyen and Kandel, 1996; Otani and Abraham, 1989). What are the targets of p38 MAPK in mediating TNF- $\alpha$ inhibition of early-LTP? Possible substrates include heat shock protein 27, that has been shown to affect actin dynamics (Rousseau et al., 1997), the microtubule-associated protein tau (Reynolds et al., 1997), and cytoplasmic phospholipase A2 (Kramer et al., 1996), the enzyme that liberates arachidonic acid from membrane phospholipids. Coogan et al. (1999) have already given some insight into this question by the finding that inhibition of the cyclooxygenase pathway by indomethacin attenuates IL-1 $\beta$ inhibition of LTP, and more specifically cyclooxygenase-2 (Murray and O'Connor, 2001) therefore suggesting a link between arachidonic acid metabolites and the impairment of LTP by IL- $1 \beta$.

In summary this paper reports that p38 MAPK detected at high basal levels in the dentate gyrus, does not have a physiological role in early or late-LTP. The role of p38 MAPK in TNF- $\alpha$ inhibition of LTP has been delineated. This work shows that p38 MAP kinase is involved in mediating the inhibitory effects of TNF- $\alpha$ on early LTP (approximately $1 \mathrm{~h}$ ). Interestingly however, the depressive effects of TNF- $\alpha$ on late LTP (approximately 1-3 h) proved to be independent of p38 MAPK. Therefore we can conclude that TNF- $\alpha$ inhibition of LTP represents a biphasic response, where the later phase may represent a proteinsynthesis dependent phase.

Acknowledgements-This work was supported by the Higher Education Authority of Ireland, the European Commission and Health Research Board of Ireland.

\section{REFERENCES}

Abel T, Nguyen PV, Barad M, Deuel TA, Kandel ER, Bourtchouladze $R$ (1997) Genetic demonstration of a role for PKA in the late phase of LTP and in hippocampus-based long-term memory. Cell 88:615626.

Albensi BC, Mattson MP (2000) Evidence for the involvement of TNF and NF-kappaB in hippocampal synaptic plasticity. Synapse 35 : 151-159.

Andreasson KI, Savonenko A, Vidensky S, Goellner JJ, Zhang Y, Shaffer A, Kaufmann WE, Worley PF, Isakson P, Markowska AL (2001) Age-dependent cognitive deficits and neuronal apoptosis in cyclooxygenase-2 transgenic mice. J Neurosci 21:8198-8209.

Beattie EC, Stellwagen D, Morishita W, Bresnahan JC, Ha BK, Von Zastrow M, Beattie MS, Malenka RC (2002) Control of synaptic strength by glial TNFalpha. Science 295:2282-2285.

Bliss TV, Collingridge GL (1993) A synaptic model of memory: longterm potentiation in the hippocampus. Nature 361:31-39.

Bolshakov VY, Carboni L, Cobb MH, Siegelbaum SA, Belardetti F (2000) Dual MAP kinase pathways mediate opposing forms of long-term plasticity at CA3-CA1 synapses. Nat Neurosci 3:11071112.

Boulanger LM, Huh GS, Shatz CJ (2001) Neuronal plasticity and cellular immunity: shared molecular mechanisms. Curr Opin Neurobiol 11:568-578.

Butler MP, Moynagh PN, O'Connor JJ (2002) Methods of detection of the transcription factor NF-kappa B in rat hippocampal slices. J Neurosci Methods 119:185-190.

Chen C, Magee JC, Bazan NG (2002) Cyclooxygenase-2 regulates prostaglandin E2 signaling in hippocampal long-term synaptic plasticity. J Neurophysiol 87:2851-2857.

Chun J (2001) Selected comparison of immune and nervous system development. Adv Immunol 77:297-322.

Coogan A, O'Connor JJ (1997) Inhibition of NMDA receptor-mediated synaptic transmission in the rat dentate gyrus in vitro by IL-1 beta. Neuroreport 8:2107-2110.

Coogan AN, O'Leary DM, O'Connor JJ (1999a) P42/44 MAP kinase inhibitor PD98059 attenuates multiple forms of synaptic plasticity in rat dentate gyrus in vitro. J Neurophysiol 81:103-110.

Coogan AN, O'Neill LA, O'Connor JJ (1999b) The P38 mitogenactivated protein kinase inhibitor SB203580 antagonizes the inhibitory effects of interleukin-1beta on long-term potentiation in the rat dentate gyrus in vitro. Neuroscience 93:57-69.

Cuenda A, Rouse J, Doza YN, Meier R, Cohen P, Gallagher TF, Young PR, Lee JC (1995) SB 203580 is a specific inhibitor of a MAP kinase homologue which is stimulated by cellular stresses and interleukin-1. FEBS Lett 364:229-233.

Cunningham AJ, Murray CA, O'Neill LA, Lynch MA, O'Connor JJ (1996) Interleukin-1 beta (IL-1 beta) and tumour necrosis factor (TNF) inhibit long-term potentiation in the rat dentate gyrus in vitro. Neurosci Lett 203:17-20.

Curran BP, Murray HJ, O'Connor JJ (2003) A role for c-jun n-terminal kinase in the inhibition of long-term potentiation by interleukin- 1 beta and long-term depression in the rat dentate gyrus in vitro. Neuroscience 118:347-357.

English JD, Sweatt JD (1996) Activation of p42 mitogen-activated protein kinase in hippocampal long term potentiation. $\mathrm{J}$ Biol Chem 271:24329-24332.

Frey U, Huang YY, Kandel ER (1993) Effects of cAMP simulate a late stage of LTP in hippocampal CA1 neurons. Science 260:1661-1664.

Huang YY, Kandel ER (1994) Recruitment of long-lasting and protein 
kinase A-dependent long-term potentiation in the CA1 region of hippocampus requires repeated tetanization. Learn Mem 1:74-82.

lida R, Saito K, Yamada K, Basile AS, Sekikawa K, Takemura M, Fujii H, Wada H, Seishima M, Nabeshima T (2000) Suppression of neurocognitive damage in LP-BM5-infected mice with a targeted deletion of the TNF-alpha gene. FASEB J 14:1023-1031.

Kassiotis G, Kollias G (2001) Uncoupling the proinflammatory from the immunosuppressive properties of tumor necrosis factor (TNF) at the p55 TNF receptor level: implications for pathogenesis and therapy of autoimmune demyelination. J Exp Med 193:427434.

Kramer RM, Roberts EF, Um SL, Borsch-Haubold AG, Watson SP, Fisher MJ, Jakubowski JA (1996) p38 mitogen-activated protein kinase phosphorylates cytosolic phospholipase A2 (cPLA2) in thrombin-stimulated platelets: evidence that proline-directed phosphorylation is not required for mobilization of arachidonic acid by cPLA2. J Biol Chem 271:27723-27729.

Mendoza-Fernandez V, Andrew RD, Barajas-Lopez C (2000) Interferon-alpha inhibits long-term potentiation and unmasks a long-term depression in the rat hippocampus. Brain Res 885:14-24.

Murray CA, Lynch MA (1998) Evidence that increased hippocampal expression of the cytokine interleukin- 1 beta is a common trigger for age- and stress-induced impairments in long-term potentiation. J Neurosci 18:2974-2981.

Murray HJ, O'Connor JJ (2001) A role for cyclooxygenase in the inhibitory effect of $1 \mathrm{~L}-1 \beta$ on long term potentiation in isolated slices of the dentate gyrus. J Physiol 109:531P.

Murray HJ, O'Connor JJ (2003) A role for COX-2 and p38 mitogen activated protein kinase in long-term depression in the rat dentate gyrus in vitro. Neuropharmacology 44:374-380.

Nguyen PV, Kandel ER (1996) A macromolecular synthesis-dependent late phase of long-term potentiation requiring cAMP in the medial perforant pathway of rat hippocampal slices. J Neurosci 16:3189-3198

Otani S, Abraham WC (1989) Inhibition of protein synthesis in the dentate gyrus, but not the entorhinal cortex, blocks maintenance of long-term potentiation in rats. Neurosci Lett 106:175-180.

Plata-Salaman CR, Ffrench-Mullen JM (1992) Interleukin-1 beta depresses calcium currents in CA1 hippocampal neurons at pathophysiological concentrations. Brain Res Bull 29:221-223.

Plata-Salaman CR, Ffrench-Mullen JM (1994) Interleukin-1 beta inhibits $\mathrm{Ca}^{2+}$ channel currents in hippocampal neurons through protein kinase C. Eur J Pharmacol 266:1-10.

Pollock J, McFarlane SM, Connell MC, Zehavi U, Vandenabeele P, MacEwan DJ, Scott RH (2002) TNF-alpha receptors simultaneously activate $\mathrm{Ca}^{2+}$ mobilisation and stress kinases in cultured sensory neurones. Neuropharmacology 42:93-106.

Reynolds CH, Nebreda AR, Gibb GM, Utton MA, Anderton BH (1997) Reactivating kinase/p38 phosphorylates tau protein in vitro. J Neurochem 69:191-198.

Rousseau S, Houle F, Landry J, Huot J (1997) p38 MAP kinase activation by vascular endothelial growth factor mediates actin reorganization and cell migration in human endothelial cells. Oncogene 15:2169-2177.

Sriram K, Matheson JM, Benkovic SA, Miller DB, Luster MI, O'Callaghan JP (2002) Mice deficient in TNF receptors are protected against dopaminergic neurotoxicity: implications for Parkinson's disease. FASEB J 16:1474-1476.

Sweatt JD (1999) Toward a molecular explanation for long-term potentiation. Learn Mem 6:399-416.

Tancredi V, D’Arcangelo G, Grassi F, Tarroni P, Palmieri G, Santoni A, Eusebi $F$ (1992) Tumor necrosis factor alters synaptic transmission in rat hippocampal slices. Neurosci Lett 146:176-178.

Vandenabeele P, Declercq W, Vanhaesebroeck B, Grooten J, Fiers W (1995) Both TNF receptors are required for TNF-mediated induction of apoptosis in PC60 cells. J Immunol 154:2904-2913.

Zhang JM, Li H, Liu B, Brull SJ (2002) Acute topical application of tumor necrosis factor alpha evokes protein kinase A-dependent responses in rat sensory neurons. J Neurophysiol 88:1387-1392. 